\title{
The Effect of Ionic Charge on the Adsorption of Organic Dyes onto Titanate Nanotubes
}

\author{
Dmitry V. Bavykin, ${ }^{\mathrm{A}, \mathrm{B}}$ Katherine E. Redmond, ${ }^{\mathrm{A}}$ Benjamin P. Nias, ${ }^{\mathrm{A}}$ \\ Alexander N. Kulak, ${ }^{\mathrm{A}}$ and Frank C. Walsh ${ }^{\mathrm{A}}$ \\ AElectrochemical Engineering Laboratory, Energy Technology Research Group, School of Engineering \\ Sciences, University of Southampton, Highfield, Southampton SO17 1BJ, UK. \\ ${ }^{B}$ Corresponding author. Email: D.Bavykin@soton.ac.uk
}

\begin{abstract}
The adsorption of dye molecules from aqueous solution onto the surface of titanate nanotubes (which have been synthesized via an alkaline hydrothermal treatment) has been studied. The ionic charge on the dye molecules was found to affect their ability to adsorb onto the titanate nanotube surface. In the case of (cationic) methylene blue, the adsorption was preferable on the negatively charged surface of titanate nanotubes rather than on positively charged $\mathrm{P} 25 \mathrm{TiO}_{2}$ nanoparticles. In the case of (anionic) Eriochrome Black T dye, the opposite trend was found. Herein, the dynamics of dye adsorption and the effect of $\mathrm{pH}$ on the adsorption capacity are considered.
\end{abstract}

Manuscript received: 10 June 2009.

Manuscript accepted: 19 August 2009.

\section{Introduction}

Protonated titanate nanotubes (H-TiNT), produced by hydrothermal treatment of powdered $\mathrm{TiO}_{2}$ or titanium metal with a concentrated aqueous $\mathrm{NaOH}$ solution, have become the target of many studies in recent years due to their unique combination of physico-chemical ${ }^{[1,2]}$ and structural ${ }^{[3]}$ properties. Nanotubular titanates, which were originally discovered by Kasuga et al. ${ }^{[4]}$ can be potentially used in applications ${ }^{[5]}$ such as catalysis, ${ }^{[6,7]}$ photocatalysis ${ }^{[8,9]}$ and electrocatalysis, hydrogen storage, ${ }^{[10,11]}$ lithium batteries, ${ }^{[12,13]}$ and solar cells..$^{[14,15]}$ The open, mesoporous morphology, high aspect ratio combined with good ion-exchange properties ${ }^{[16,17]}$ and moderate electroconductivity render nanostructured titanates useful in nanoscale design. Examples include decoration of nanotubes with nanoparticles, ${ }^{[18]}$ functionalization of nanotubes, ${ }^{[19]}$ and manufacture of composites. ${ }^{[20]}$

A detailed knowledge of the physico-chemical properties of the surface of nanotubular titanates is essential because the high surface area of nanotubes is used, in most applications, as a support for active materials. An understanding of the underlying principles controlling the adsorption of active species on the surface of nanostructured titanates should provide an important tool for the targeted functionalization of nanotubes.

In an aqueous suspension, nanotubular titanates tend to develop a negative zeta potential due to the dissociation of titanic acid according to the following reaction: ${ }^{[21]}$

$$
\mathrm{H}_{2} \mathrm{Ti}_{3} \mathrm{O}_{7} \leftrightarrows \mathrm{H}^{+}+\mathrm{HTi}_{3} \mathrm{O}_{7}^{-}
$$

This phenomenon greatly affects the ability of charged molecules to adsorb on the surface of nanotubes. The affinity of species in the cationic form is much better than that of anionic species, indicating the major role of electrostatic interactions between adsorbent and adsorptives during adsorption from aqueous solution. This principle has allowed improved methods for the deposition of precious metals on the surface of titanate nanotubes using metal precursors in cationic form. ${ }^{[22]}$ Uniformly distributed metal nanoparticles, densely loaded on the surface of nanotubes, could be achieved. The use of a negatively charged precursor in aqueous solution (e.g. $\left[\mathrm{AuCl}_{4}\right]^{-}$or $\left.\left[\mathrm{PtCl}_{6}\right]^{2-}\right),{ }^{[23,24]}$ tends to result in a less uniform distribution of metal nanoparticles and difficulties in obtaining high values of metal loading while maintaining a high dispersity of metal.

Adsorption of dye molecules from aqueous solution onto the titanate nanotubes should follow the same principle of electrostatic interactions. Unfortunately, there is only limited amount of published, systematic works ${ }^{[25]}$ showing the effect of the surface charge on dye molecules on their ability to adsorb on the surface of titanate nanotubes. Such studies would help to improve the performance of dye sensitized cells, by tailored selection of a dye with a higher affinity towards the surface of titanate nanotubes, as compared to previous studies in which negatively charged dyes were characterized by a limited adsorption on the surface of nanotubes. ${ }^{[26-29]}$

In this work, the adsorption of cationic and anionic dyes from aqueous solution onto the surface of negatively charged titanate nanotubes and positively charged $\mathrm{TiO}_{2}$ nanoparticles (Degussa $\mathrm{TiO}_{2} \mathrm{P} 25$ ) at $25^{\circ} \mathrm{C}$ was studied. The effect of solution $\mathrm{pH}$ and nanotube length on the kinetics of dye adsorption into titanate nanotubes was also examined.

\section{Experimental}

Reagents

Titanium dioxide (anatase, $\mathrm{TiO}_{2}$ ), sodium hydroxide $(\mathrm{NaOH})$, methylene blue (MB), Eriochrome Black T (EBT) (Fig. 1), and hydrochloric acid $(\mathrm{HCl})$ pure grade, were obtained from Aldrich and were used without further purification. Nanoparticulate P25 $\mathrm{TiO}_{2}$ was obtained from Degussa. Standard $\mathrm{pH}$ buffer solutions were obtained from Fisher Chemicals. 
Preparation of Protonated Titanate Nanotubes and Nanofibres

The preparation of titanate nanotubes was based on the alkaline hydrothermal method proposed by Kasuga et al. ${ }^{[4]}$ and further developed in our laboratories towards lower temperature using $\mathrm{KOH}-\mathrm{NaOH}$ mixture, ${ }^{[30,31]}$ ultimately allowing to use reflux instead of autoclave apparatuses. Titanium dioxide ( $3 \mathrm{~g}$, anatase) was mixed with of $49 \mathrm{~cm}^{3}$ of $10 \mathrm{~mol} \mathrm{dm}{ }^{-3} \mathrm{NaOH}$ and $1 \mathrm{~cm}^{3}$ of $10 \mathrm{~mol} \mathrm{dm}^{-3} \mathrm{KOH}$ aqueous solutions then placed in PFA (a perfluoroalkoxy polymer) round-bottom flask equipped with thermometer and refluxed at $100^{\circ} \mathrm{C}$ for $48 \mathrm{~h}$. The white, powdery titanate nanotubes produced were thoroughly washed with water until the washing solution achieved $\mathrm{pH}$ 7. In order to convert nanostructured titanates into their protonated form, the powder was washed with excess of $0.1 \mathrm{~mol} \mathrm{dm}^{-3} \mathrm{HCl}$ for over $30 \mathrm{~min}$ until a stable $\mathrm{pH}$ of 2 was reached, followed by water washing to $\mathrm{pH}$ 5. The sample was dried in air at $120^{\circ} \mathrm{C}$.

\section{Measurement of Dye Adsorption}

For measurements of the adsorption isotherm, $0.1 \mathrm{~g}$ of a powdered sample was placed in a glass vial and $(10-x ; x$ refers to the volume (in $\mathrm{cm}^{3}$ ) of added solution of dye) $\mathrm{cm}^{3}$ water were added followed by addition of $x \mathrm{~cm}^{3}$ of $0.01 \mathrm{~mol} \mathrm{dm}^{-3}$ solution of dye. The mixture was stirred and kept for $24 \mathrm{~h}$ at $25^{\circ} \mathrm{C}$ to ensure equilibration. The liquid was then separated from the solid using filtration or decanting and the concentration of dye in the liquid was determined using a UV-visible spectrometer (Neosys 2000, Scinco); absorption bands at $665 \mathrm{~nm}$ and at $550 \mathrm{~nm}$ were used for detection of MB and EBT respectively. The amount of dye adsorbed on the surface of the powder, $a$, in mol per mol units was calculated using the formula (Eqn 2):

$$
a=\frac{M\left(\mathrm{TiO}_{2}\right)\left(C_{0}-C\right) V}{m},
$$

where $C_{0}$ and $C$ are the initial and equilibrium concentrations of dye in solution, $V$ is the volume of solution, $m$ is the mass of solid sample powder, and $M\left(\mathrm{TiO}_{2}\right)$ is molar mass of $\mathrm{TiO}_{2}$, which is $80 \mathrm{~g} \mathrm{~mol}^{-1}$.

The kinetic curves for dye molecule adsorption on the surface of titanate nanotubes were obtained using the following method. In a $100 \mathrm{~cm}^{3}$ beaker, $0.8 \mathrm{~cm}^{3}$ of $0.01 \mathrm{~mol} \mathrm{dm} \mathrm{dm}^{-3}$ dye was mixed with $19.2 \mathrm{~cm}^{3}$ of distilled water. Under vigorous stirring, $0.1 \mathrm{~g}$ of titanate nanotubes was added. The decay of dye concentration in aqueous solution was monitored by taking a $0.2 \mathrm{~cm}^{3}$ aliquots at selected times. Before taking the aliquot, stirring was stopped for $30 \mathrm{~s}$ to settle the titanate powder. The aliquot was diluted in $5 \mathrm{~cm}^{3}$ of standard buffer $(\mathrm{pH}=4)$ and the concentration of the dye was determined using a UV-visible spectrometer.

\section{Sample Characterization}

Transmission electron microscopy (TEM) images were obtained using a JEOL 3010-TEM transmission electron microscope. The powder sample was 'dry' deposited onto a copper grid covered with a perforated carbon film. Scanning electron microscopy (SEM) images were obtained with a JEOL 6500 FEG-SEM scanning electron microscope. The sample was dispersed in water, deposited on flat silicon wafers then dried at $25^{\circ} \mathrm{C}$. XRD patterns were recorded using a Bruker AXS D8 Discoverer X-ray diffractometer, with $\mathrm{Ni}$-filtered $\mathrm{Cu}-\mathrm{K}_{\alpha}$ radiation $(\lambda=0.154 \mathrm{~nm})$ and a graphite monochromator, in the $2 \theta$ range from $5^{\circ}$ to $40^{\circ}$. (a)

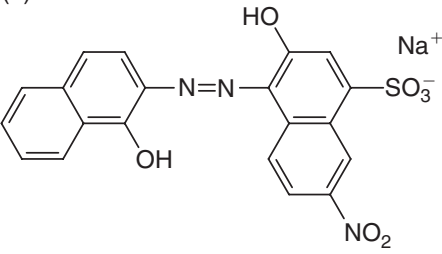

(b)

Fig. 1. Dyes used in this study. (a) Eriochrome Black T, (b) methylene blue.

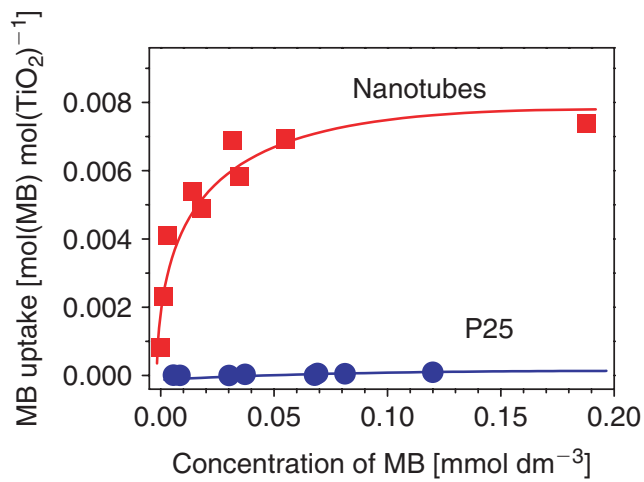

Fig. 2. Isotherm for methylene blue (MB) adsorption onto the surface of (घ) titanate nanotubes and $(0) \mathrm{P}^{2} 5 \mathrm{TiO}_{2}$ at $25^{\circ} \mathrm{C} . \mathrm{pH}$ values in the range from 4 to 5 .

\section{Results and Discussion}

The isotherms of $\mathrm{MB}$ adsorption on the surface of titanate nanotubes and $\mathrm{P} 25 \mathrm{TiO}_{2}$ nanoparticles from aqueous solution at $25^{\circ} \mathrm{C}$ are vshown in Fig. 2. The adsorption isotherms followed Langmuir-type adsorption, according to the following (Eqn 3):

$$
a=\frac{a_{S} K_{L} C}{1+K_{L} C},
$$

where $a_{S}$ corresponds to the amount of dye forming monolayer on the surface of adsorbent, and $K_{L}$ is the constant of adsorption. When the concentration of MB in solution exceeds $0.05 \mathrm{mmol} \mathrm{dm}^{-3}$ the surface of titanate nanotubes has become saturated with adsorbed MB molecules. The amount of adsorbed $\mathrm{MB}$ on the surface of nanotubes can be estimated as $\sim 0.008 \mathrm{~mol}(\mathrm{MB}) \mathrm{mol}\left(\mathrm{TiO}_{2}\right)^{-1}$. In contrast, the $a_{s}$ value for $\mathrm{MB}$ on the surface of $\mathrm{P} 25$ nanoparticles was found to be almost two orders of magnitude smaller $\left(\sim 6 \times 10^{-5} \mathrm{~mol}(\mathrm{MB}) \mathrm{mol}\right.$ $\left.\left(\mathrm{TiO}_{2}\right)^{-1}\right)$. Values of the adsorption constant $\left(K_{L}\right)$ and saturation concentration $\left(a_{S}\right)$ for nanotubes and nanoparticles, estimated by fitting data from Fig. 2 to Eqn (3), are shown in Table 1. Such a large difference in $a_{s}$ values is difficult to explain by the difference in values of specific surface area alone.

Fig. 3 shows the isotherm for EBT adsorption from aqueous solution on the surface of nanotubes and nanoparticles. From Eqn (3), the amounts of dye in monolayer $\left(a_{s}\right)$ on the surface of nanotubes can be estimated (Table 1). Despite the fact that the specific surface area of nanoparticles is almost five times smaller than that for nanotubes, the amount of EBT on the surface of nanoparticles is higher than on the surface of nanotubes during adsorption from aqueous solution.

In aqueous solution, both of the dyes experience electrolytic dissociation. For MB, this results in the cationic form, whereas the EBT exists in the anionic form (Fig. 1) over a wide range of $\mathrm{pH}$. At the same time, titanate nanotubes and $\mathrm{TiO}_{2}$ nanoparticles (P25) suspended in aqueous media develop a zeta potential, 
Table 1. Adsorption properties of titanate nanotubes for two organic dyes

\begin{tabular}{|c|c|c|c|c|c|c|c|c|}
\hline Dye & Adsorbent & $K_{L}^{\mathrm{A}}\left[\mathrm{dm}^{3} \mathrm{mmol}^{-1}\right]$ & $a_{s}^{\mathrm{A}}\left[\operatorname{mol}(\mathrm{dye}) \operatorname{mol}\left(\mathrm{TiO}_{2}\right)^{-1}\right]$ & BET area $\left[\mathrm{m}^{2} \mathrm{~g}^{-1}\right]$ & $n_{d y e^{\mathrm{B}}}$ & $S_{d y e}{ }^{\mathrm{C}}\left[\mathrm{nm}^{2}\right]$ & \multicolumn{2}{|c|}{ Charges on dye/support } \\
\hline MB & H-TiNT & 285 & 0.008 & 250 & 1200 & 2.63 & + & - \\
\hline EBT & H-TiNT & 31 & 0.002 & 250 & 300 & 10.5 & - & - \\
\hline MB & $\mathrm{TiO}_{2}(\mathrm{~B}) \mathrm{NT}$ & 66 & 0.0056 & $180^{\mathrm{D}}$ & 1100 & 2.65 & + & - \\
\hline MB & P25 & 13 & $6 \times 10^{-5}$ & 50 & 15 & 136 & + & + \\
\hline EBT & P25 & 132 & 0.014 & 50 & 3500 & 0.58 & - & + \\
\hline
\end{tabular}

${ }^{\text {A }}$ Obtained using Eqn (3).

${ }^{B}$ Obtained using Eqn (4) for nanotubes and Eqn (6) for nanoparticles.

${ }^{\mathrm{C}}$ Obtained using Eqn (5) for nanotubes and Eqn (7) for nanoparticles.

${ }^{D}$ Estimated from Ref. [43].

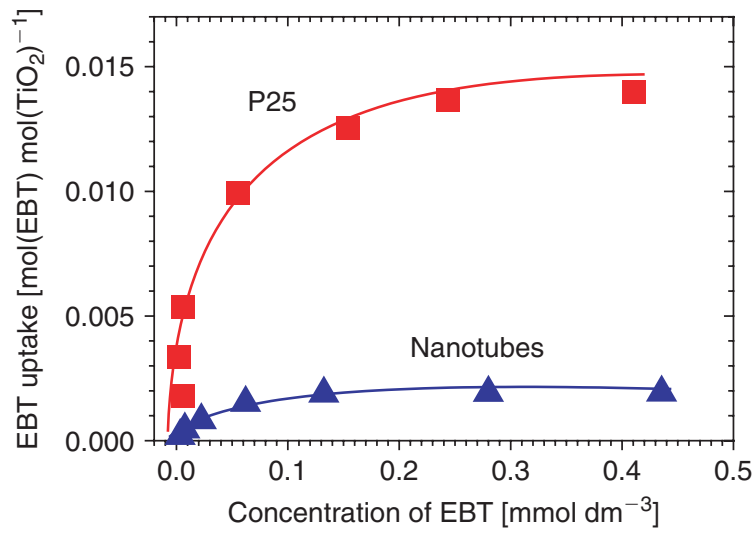

Fig. 3. Isotherms for Eriochrome Black $\mathrm{T}(\mathrm{EBT})$ adsorption onto the surface of $(\triangle)$ titanate nanotubes and $(\square) \mathrm{P}_{2} 5 \mathrm{TiO}_{2}$ at $25^{\circ} \mathrm{C}$. pH values in the range from 4 to 5 .

which is negative for nanotubes ${ }^{[21]}$ and positive for nanoparticles (isoelectric point is $6.5^{[32]}$ ) at $\mathrm{pH}$ values in the range from 4 to 5 . When the sign of the charge between dye and adsorbent is different it results in more favourable adsorption, compared to when both adsorbent and adsorptive have the same sign of charge. This indicates that electrostatic interactions dominate during adsorption of charged dyes from aqueous media.

The surface of multilayered wall titanate nanotubes, its area, accessibility and properties, depends on the method of study. For example, nitrogen and water adsorption studies ${ }^{[33,34]}$ have revealed that only the external and internal geometrical surfaces of titanate nanotubes are accessible to these molecules positioning the nanotubes to the mesoporous class of materials. Indeed, the typical internal diameter (hollow) of titanate nanotubes is in the range of $3-8 \mathrm{~nm}$, whereas the average diameter pores, which have been formed between nanotubes by their external surface is slightly larger and depends very much on the way that the nanotubes self-assemble. ${ }^{[35]}$ The total specific surface area of titanate nanotubes, as determined by nitrogen adsorption, is $\sim 250 \mathrm{~m}^{2} \mathrm{~g}^{-1}$ with a total specific pore volume of $\sim 0.7 \mathrm{~cm}^{3} \mathrm{~g}^{-1}$.

The walls of the titanate nanotubes have a multilayered structure. The layers of the crystallized titanate consist of edge- and corner-sharing $\mathrm{TiO}_{6}$ octahedra building up zigzag structures. ${ }^{[36]}$ The distance between the layers varies in range from $0.72 \mathrm{~nm}$ in the protonated form, to $0.91 \mathrm{~nm}$ in the alkaline metal substituted form. ${ }^{[17]}$ In contrast to nitrogen and water, smaller molecules such as hydrogen, ${ }^{[11]}$ or alkaline metal cations, ${ }^{[17]}$ can access the cavities situated inside the wall of nanotubes between the layers. The rate of hydrogen or alkaline metal intercalation between the layers is in range of several tens of minutes to several hours.

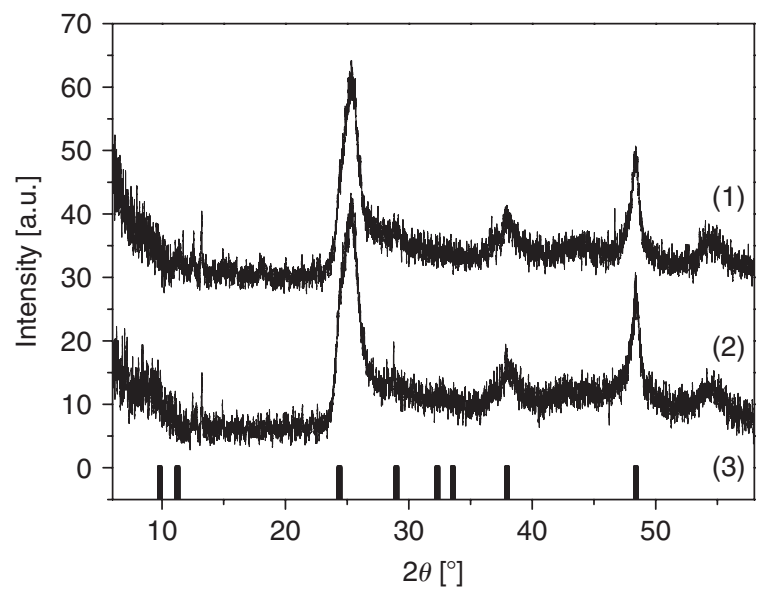

Fig. 4. XRD pattern of (1) titanate nanotubes with deposited methylene blue (MB) and (2) initial protonated titanate nanotubes. (3) $\mathrm{H}_{2} \mathrm{Ti}_{3} \mathrm{O}_{7}$ reflexions according to Ref. [36].

The transport of intercalating species occurs along the length of the nanotubes.

It is important to understand the nature of the adsorption site during sorption from aqueous solution into titanate nanotubes; whether or not the adsorbate can intercalate between the layers into the wall or adsorb only on the geometrical surface. Recently, it was shown that cationic, flat dye molecules can intercalate between the flat layers of solid lepidocrocite titanates, resulting in an increase of interlayer distance from $0.79 \mathrm{~nm}$ to $1.70 \mathrm{~nm}$ for $\mathrm{H}_{2} \mathrm{Ti}_{3} \mathrm{O}_{7}{ }^{[37]}$ During intercalation, preferred orientation of adsorbed dye molecules occurs resulting in polarization of the adsorption. ${ }^{[38]}$

In the case of titanate nanotubes, curvature of the layers can result in inhibition of dye intercalation between the layers. Fig. 4 shows XRD patterns of titanate nanotubes before and after adsorption of $\mathrm{MB}$ on their surface. The weak reflex at $\sim 10^{\circ}$ has (200) Miller index, which is related to diffraction from planes corresponding to the layers in the wall of the nanotubes (Fig. 5b). If intercalation of dye molecules between these layers occurred it would result in shift of (200) reflex into the range of smaller angles. The comparisons of XRD patterns of titanate nanotubes with and without dye, suggest the absence of structural changes in crystal structures of titanates. This means that, due to the deficiency of significant changes of interlayer distance in titanate nanotubes during adsorption of $\mathrm{MB}$, only geometrical area of nanotubes can be considered to be available for the adsorption of dye molecules. 

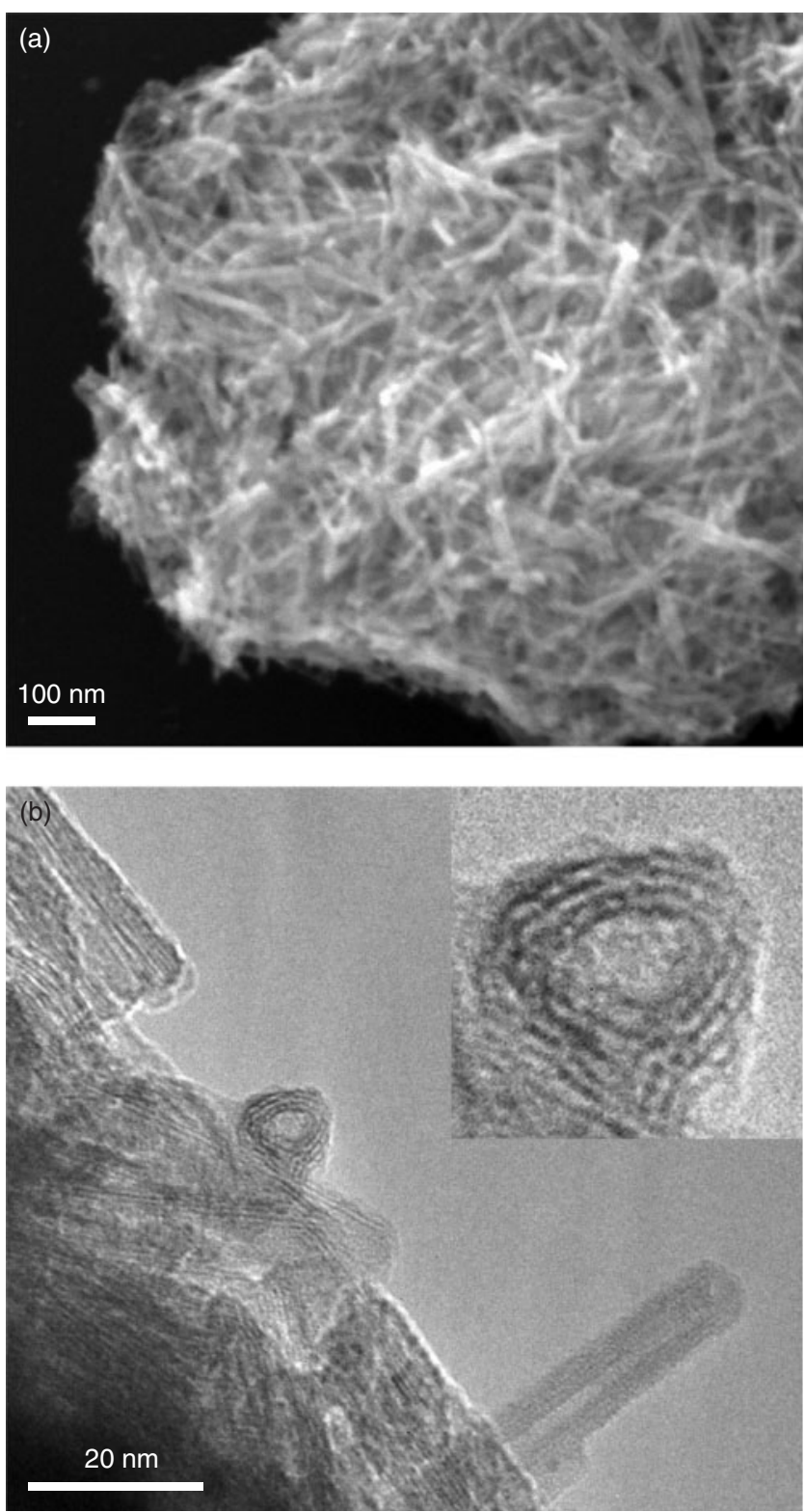

Fig. 5. Electron microscopy images of titanate nanotubes; (a) SEM showing nanotubes bundles and (b) TEM, showing individual nanotubes.

\section{Estimation of MB Surface Density}

Because the geometry of titanate nanotubes is well characterized, ${ }^{[2]}$ it is possible to use $a_{s}$ values to estimate the average number of dye molecules occupying the surface of one titanate nanotube $\left(n_{\text {dye }}\right)$ via Eqn (4):

$$
n_{\text {dye }}=a_{s} \frac{\pi \rho l N_{A}}{2 M\left(\mathrm{TiO}_{2}\right)}\left(d_{e x}^{2}-d_{i n}^{2}\right),
$$

where $\rho$ is the density of titanate nanotubes, $l$ is the average length of nanotube, $d_{e x}$ and $d_{i n}$ are external and internal diameter of nanotubes respectively, and $M\left(\mathrm{TiO}_{2}\right)$ is the molar mass of $\mathrm{TiO}_{2}\left(80 \mathrm{~g} \mathrm{~mol}^{-1}\right)$. The density of single titanate nanotubes can be estimated from the parameters of unit cell of $\mathrm{H}_{2} \mathrm{Ti}_{3} \mathrm{O}_{7}(a=1.602 \mathrm{~nm}, b=0.375 \mathrm{~nm}, c=0.919 \mathrm{~nm}$, and $\beta=101.5^{\circ[36]}$ ) and taking into account that four molecules of titanate occupy one unit cell. The estimated density is $3.16 \mathrm{~g} \mathrm{~cm}^{-3}$, which is slightly smaller than the value of solid sodium trititanate ${ }^{[39]}\left(3.43 \mathrm{~g} \mathrm{~cm}^{-3}\right)$. Using the following typical parameters for titanate nanotubes $\left(d_{i n}=3 \mathrm{~nm}, d_{e x}=7 \mathrm{~nm}\right.$, $l=100 \mathrm{~nm}$ ) (Fig. $5 \mathrm{~b}$ ), the approximate number of MB molecules occupying the surface of one titanate nanotubes $\left(n_{d y e}\right)$, when saturation has been achieved, can be estimated as 1200 .

Assuming that MB molecules are uniformly distributed as a monolayer on the surface of the nanotubes, and taking into account that the surface area of a typical nanotubes is equal to $\pi l\left(d_{e x}+d_{i n}\right)$, it is possible to estimate the average surface occupied by one dye molecule $S_{d y e}$ using the following formula (Eqn 5):

$$
S_{d y e}=\frac{2 M\left(\mathrm{TiO}_{2}\right)\left(d_{e x}+d_{i n}\right)}{a_{S} N_{A} \rho\left(d_{e x}^{2}-d_{i n}^{2}\right)} .
$$

During adsorption of MB from aqueous solution on the surface of titanate nanotubes in saturation each molecule covers $2.63 \mathrm{~nm}^{2}$ of nanotube area. This $S_{d y e}$ value is relatively small and corresponds to very dense packing of MB molecules on the surface of the titanate nanotubes. For comparison, the theoretical maximal value of $S_{d y e}$, based on molecular dimensions for MB molecules lying flat on a solid surface in a close packed monolayer, would be $1.6 \mathrm{~nm}^{2}$, whereas an experimental $S_{d y e}$ value of $1.97 \mathrm{~nm}^{2}$ has been obtained for MB adsorbed on the surface of carbon. ${ }^{[40]}$

Similar geometrical considerations for spheroidal $\mathrm{P} 25 \mathrm{TiO}_{2}$ nanoparticles allows values of $n_{d y e}$ and $S_{d y e}$ to be estimated using the following formulae (Eqns 6 and 7):

$$
\begin{aligned}
& n_{\text {dye }}=a_{s} \frac{\pi \rho N_{A} d^{3}}{6 M\left(\mathrm{TiO}_{2}\right)}, \\
& S_{\text {dye }}=\frac{6 M\left(\mathrm{TiO}_{2}\right)}{a_{s} N_{A} \rho d},
\end{aligned}
$$

where $d$ is the diameter of P25 nanoparticles $(\sim 25 \mathrm{~nm})$. The numerical values for $a_{s}, n_{d v e}$, and $S_{d y e}$, estimated from MB and EBT adsorption on nanotubes and nanoparticles (Figs 2 and 3) using Eqns (3)-(7) are summarized in Table 1. Analysis of these values shows that when the sign of zeta potential of the adsorbent is opposite to the sign of the dye ion charge, the surface area $S_{d y e}$ is very small, compared with the case when both zeta potential and ion charge have the same sign. During adsorption of EBT on the surface of P25, the value of $S_{d y e}$ is smaller than geometrical surface area of the dye molecule. This probably means that, during adsorption, the dye molecules form agglomerates on the surface, resulting in an overestimation of the number of molecules in a monolayer $\left(n_{d y e}\right)$.

It is apparent that electrostatic interactions between dye and surface dominate the character of the adsorption from aqueous solution. This allows strategic design of dye molecules to achieve compact packaging of dye molecules on the surface of nanostructured solids, potentially resulting in self assembling and improvement of resonant energy transfer between photoexcited molecules required for molecular light harvesting systems. ${ }^{[41]}$

Titanate nanotubes decorated with dye molecules have potential application in dye sensitized solar cells. In typical cell manufacturing processes, the suspension of nanotubes is deposited on the surface of electro-conductive glass followed by calcination at $450^{\circ} \mathrm{C}$. Such high-temperature thermal treatments results in structural and morphological changes of nanotubes, ${ }^{[5,42]}$ which may affect the affinity of dye molecules for the surface of the semiconductor. According to recent reports, ${ }^{[43]}$ annealing of protonated titanate nanotubes ( $\mathrm{H}$-TiNT) at $400^{\circ} \mathrm{C}$ results in a $34 \%$ decrease of their specific surface area, accompanied by loss of 


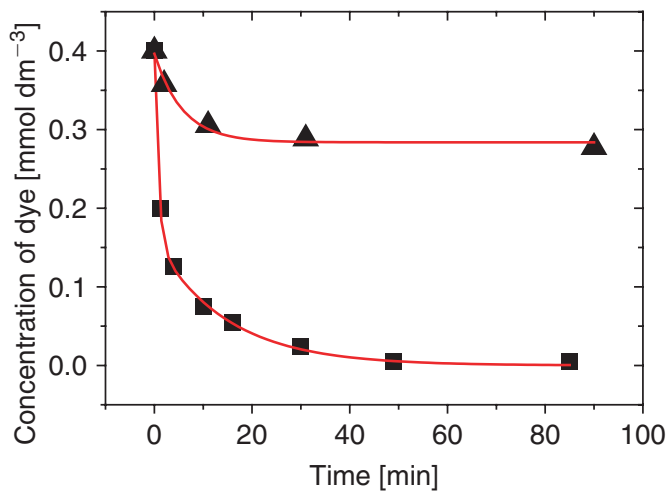

Fig. 6. The concentration of ( $\mathbf{\square})$ methylene blue and (A) Eriochrome Black $\mathrm{T}$ in aqueous solutions $\left(20 \mathrm{~cm}^{3}\right)$ as a function of time following the addition of $0.1 \mathrm{~g}$ titanate nanotubes at $25^{\circ} \mathrm{C}$. pH values in the range from 4 to 5 .

water molecules and transformation of titanates to monoclinic $\mathrm{TiO}_{2}$ (B), ${ }^{[42]}$ maintaining nanotubular morphology. Analysis of MB adsorption isotherm on the surface of annealed samples have revealed that calcination of protonated nanotubes in air at $400^{\circ} \mathrm{C}$ for $24 \mathrm{~h}$ results in $\sim 30 \%$ decrease of the amount of MB molecules forming the monolayer on the surface of nanotubes $\left(a_{S}\right)$ and $75 \%$ decrease of adsorption constant $K_{L}$ (Table 1). The decrease in $a_{s}$ is correlated with decrease in specific surface area of the nanotubes, whereas significant changes in the adsorption constant can be attributed to modification of the nature of adsorption sites due to the loss of $\mathrm{OH}$ groups during calcination.

\section{The Kinetics of Dye Adsorption}

The studies of the dynamics of dye molecule adsorption on the surface of titanate nanotubes can provide additional insight to the mechanism of adsorption. Fig. 6 shows the kinetic curves of the dye concentration in aqueous solution after addition of titanate nanotubes. Such an addition results in a gradual decrease of dye concentration due to the adsorption of dye on the surface of nanotubes. In case of EBT adsorption, the kinetic curve follows the single exponent decay law with a characteristic time $\left(t_{1}\right)$ close to $5 \mathrm{~min}$. The offset concentration of dye corresponds to the equilibrium concentration $(C)$ from Eqn (2).

In contrast, the addition of titanate nanotubes to the solution of MB results in significant decrease in the initial concentration of MB. The kinetic curve can, thus, be better fitted using second order exponential decay with two characteristic times $\left(t_{1}\right.$ and $\left.t_{2}\right)$ $0.8 \mathrm{~min}$ and $15 \mathrm{~min}$ respectively. The typical time scale for dye adsorption on the surface of titanate nanotubes is in the range of tens of minutes, which is in the same order of magnitude as the characteristic time of alkaline ion intercalation into the wall of titanate nanotubes. ${ }^{[17]}$

The solid powdered titanate nanotubes, as prepared, are usually agglomerated into the large secondary particles (Fig. 5a). The diffusion of dye into the pores between nanotubes, as well as inside nanotubes, could be a time limiting process. The ultrasonic treatment of suspended titanate nanotubes results in breaking of agglomerates as well as shortening of nanotubes. ${ }^{[35]}$ This can potentially increase the rate of dye adsorption on the surface of nanotubular titanates. Fig. 7 shows the kinetic curves of $\mathrm{MB}$ adsorption on the surface of initial nanotubes and nanotubes treated with ultrasound. The breaking of agglomerates and shortening of nanotubes was found to result in a decrease of $t_{1}$ without a significant change in $t_{2}(0.15 \mathrm{~min}$ and $12 \mathrm{~min}$ respectively). This demonstrates the complexity of the adsorption process including several stages: diffusion of dye molecules

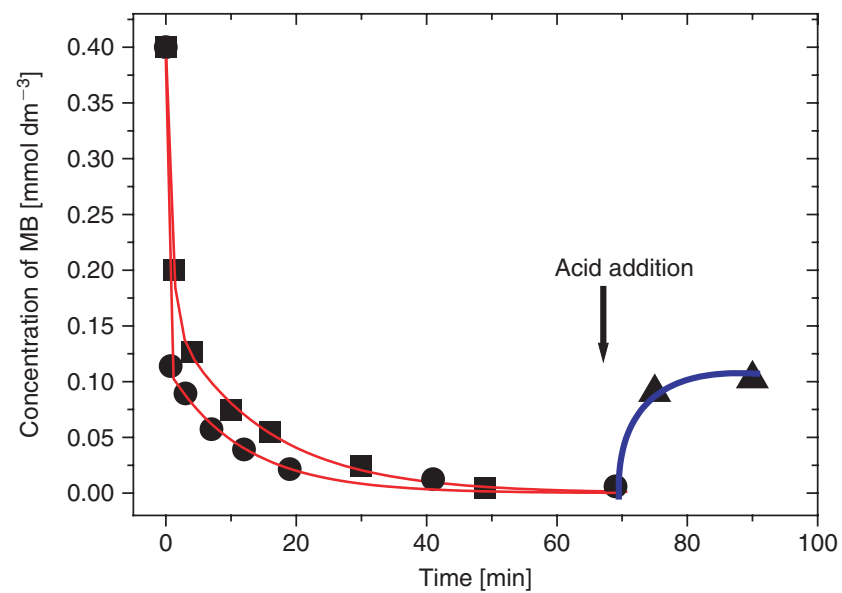

Fig. 7. The concentration of methylene blue (MB) in $20 \mathrm{~cm}^{3}$ aqueous solution as a function of time after addition of $0.1 \mathrm{~g}$ titanate nanotubes ( $\square$ ) initial tubes, (-) sonicated tubes at $25^{\circ} \mathrm{C}$. $\mathrm{pH}$ is in range from 4 to 5 . (A) change to $\mathrm{pH} 1.5$ by addition of $\mathrm{HCl}$ to the sonicated nanotubes saturated with $\mathrm{MB}$.

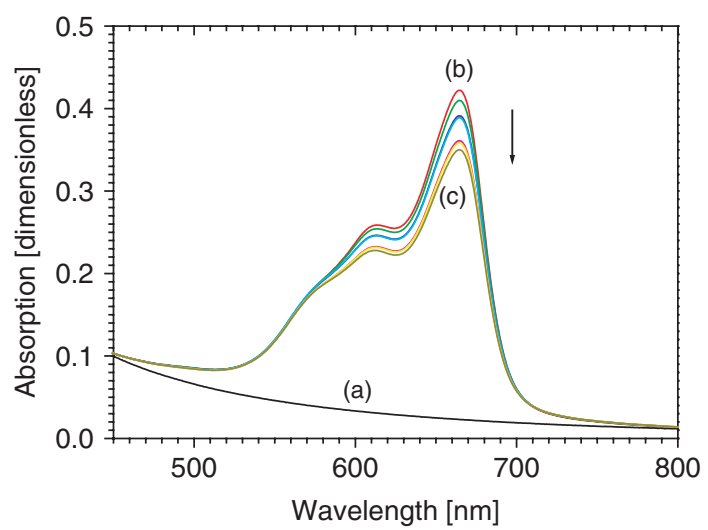

Fig. 8. Optical spectra of aqueous colloidal titanate nanotubes $\left(\sim 1 \times 10^{-3} \mathrm{~mol} \mathrm{dm}^{-3} \mathrm{Ti}\right)$, (a) after addition of $6 \times 10^{-6} \mathrm{~mol} \mathrm{dm}^{-3} \mathrm{MB}$ at different times of adsorption. From (b) to (c) the time of adsorption corresponds to $1,5,15,25,35,45,55 \mathrm{~min}$. Temperature is $25^{\circ} \mathrm{C}$. Optical path $=1 \mathrm{~cm}$.

within nanotubes, agglomeratation, and interaction of dye with the surface of nanotubes.

During the adsorption of the MB on the surface of protonated titanate nanotubes, there was no significant change in the $\mathrm{pH}$ of the solution, in contrast to the case of intercalation of alkaline metal cations, ${ }^{[17]}$ where significant variations of $\mathrm{pH}$ were observed due to ion exchange. This indicates that adsorption of cationic dye does not follow a simple ion-exchange mechanism which releases protons into solution.

The decrease in $\mathrm{pH}$ by addition of $\mathrm{HCl}$ resulted in a decrease in the amount of dye adsorbed on the surface of nanotubes (Fig. 7). The acidification of the solution resulted in a change in the zeta potential of the titanate nanotubes to positive values, causing the appearance of repulsive electrostatic forces and desorption of dye. However, the higher temperature treatment of nanotubes saturated with $\mathrm{MB}$ and dried at $120^{\circ} \mathrm{C}$, results in irreversible adsorption of MB. Such a sample showed no desorption of dye even at low $\mathrm{pH}$.

In Fig. 8 optical spectra of aqueous colloids of titanate nanotubes after addition of MB are shown. During adsorption of MB molecules on the surface of nanotubes, no significant change of the dye band structure was observed (Figs $7 \mathrm{c}$ and $8 \mathrm{~b}$ ). This result 
is in agreement with those recently reported elsewhere. ${ }^{[4]}$ The position of the peak at $665 \mathrm{~nm}$ and the shape of the spectrum remained the same. Taking into account that the absorption signal in the colloidal solution is the superposition of absorption signals from MB molecules in solution and on surface of nanotubes, and assuming that there is no chemical reaction resulting in decomposition of $\mathrm{MB}$, the decrease of the absorption signal (from Fig. 7b to Fig. 7c) can be interpreted as a decrease of dye molecule oscillator strength due to adsorption or probable reorganization of dye molecules on the surface of nanotubes. The apparent decrease of the MB extinction coefficient at $665 \mathrm{~nm}$ is $\sim 15 \%$.

\section{Conclusions}

1. The importance of electrostatic interaction between titanate nanotubes suspended in aqueous solution and dye molecules has been demonstrated during dye adsorption.

2. The favourable situation for dye adsorption would be when the surface charge of nanotubes and the charge of dye ions in aqueous solution are opposite.

3. The adsorption of methylene blue cations on the surface of negatively charged titanate nanotubes results in formation compact monolayer of the dye where each of the molecules is occupying the area of $2.63 \mathrm{~nm}^{2}$.

4. These results allow a degree of control of dye adsorption on the surface of nanostructured titanate by selecting an appropriate ionic form of the dye.

\section{Acknowledgement}

The authors gratefully acknowledge financial support from the EPSRC, UK (grant EP/F044445/1, 'A hydrothermal route to metal oxide nanotubes: synthesis and energy conversion application').

\section{References}

[1] X. Chen, S. S. Mao, Chem. Rev. 2007, 107, 2891. doi:10.1021/ CR0500535

[2] D. V. Bavykin, J. M. Friedrich, F. C. Walsh, Adv. Mater. 2006, 18, 2807. doi:10.1002/ADMA.200502696

[3] Q. Chen, L.-M. Peng, Int. J. Nanotechnology 2007, 4, 44 doi:10.1504/IJNT.2007.012314

[4] T. Kasuga, M. Hiramatsu, A. Hoson, T. Sekino, K. Niihara, Langmuir 1998, 14, 3160. doi:10.1021/LA9713816

[5] D. V. Bavykin, F. C. Walsh, Eur. J. Inorg. Chem. 2009, 8, 977. doi:10.1002/EJIC.200801122

[6] D. V. Bavykin, A. A. Lapkin, P. K. Plucinski, J. M. Friedrich, F. C. Walsh, J. Catal. 2005, 235, 10. doi:10.1016/J.JCAT.2005.07.012

[7] V. Idakiev, Z. Y. Yuan, T. Tabakova, B. L. Su, Appl. Catal. A 2005, 281, 149. doi:10.1016/J.APCATA.2004.11.021

[8] J. Yu, H. Yu, B. Cheng, X. Zhao, Q. Zhang, J. Photochem. Photobiol. Chem. 2006, 182, 121. doi:10.1016/J.JPHOTOCHEM.2006.01.022

[9] H. Langhuan, S. Zhongxin, L. Yingliang, J. Cer. Soc. Jap. 2007, 115, 28. doi:10.2109/JCERSJ.115.28

[10] S. H. Lim, J. Luo, Z. Zhong, W. Ji, J. Lin, Inorg. Chem. 2005, 44, 4124. doi:10.1021/IC0501723

[11] D. V. Bavykin, A. A. Lapkin, P. K. Plucinski, J. M. Friedrich, F. C. Walsh, J. Phys. Chem. B 2005, 109, 19422. doi:10.1021/JP0536394

[12] A. R. Armstrong, G. Armstrong, J. Canales, P. G. Bruce, J. Power Sources 2005, 146, 501. doi:10.1016/J.JPOWSOUR.2005.03.057

[13] F. Cheng, J. Chen, J. Mater. Res. 2006, 21, 2744. doi:10.1557/ JMR.2006.0337

[14] Y. Ohsaki, N. Masaki, T. Kitamura, Y. Wada, T. Okamoto, T. Sekino, K. Niiharab, S. Yanagida, Phys. Chem. Chem. Phys. 2005, 7, 4157 doi:10.1039/B511016E
[15] P. T. Hsiao, K. P. Wang, C. W. Cheng, H. Teng, J. Photochem. Photobiol Chem. 2007, 188, 19. doi:10.1016/J.JPHOTOCHEM.2006.11.013

[16] X. Sun, Y. Li, Chem. Eur. J. 2003, 9, 2229. doi:10.1002/CHEM. 200204394

[17] D. V. Bavykin, F. C. Walsh, J. Phys. Chem. C 2007, 111, 14644 doi:10.1021/JP073799A

[18] M. Hodos, E. Horvath, H. Haspel, A. Kukovecz, Z. Konya, I. Kiricsi, Chem. Phys. Lett. 2004, 399, 512. doi:10.1016/J.CPLETT.2004. 10.064

[19] M. T. Byrne, J. E. McCarthy, M. Bent, R. Blake, Y. K. Gun'ko, E. Horvath, Z. Konya, A. Kukovecz, I. Kiricsi, J. N. Coleman, J. Mater. Chem. 2007, 17, 2351. doi:10.1039/B612886F

[20] H. Yu, J. Yu, B. Cheng, J. Lin, J. Hazard. Mater. 2007, 147, 581 doi:10.1016/J.JHAZMAT.2007.01.054

[21] D. V. Bavykin, E. V. Milsom, F. Marken, D. H. Kim, D. H. Marsha, D. J. Riley, F. C. Walsh, K. H. El-Abiary, A. A. Lapkin, Electrochem. Commun. 2005, 7, 1050. doi:10.1016/J.ELECOM.2005.07.010

[22] F. C. Walsh, D. V. Bavykin, L. Torrente-Murciano, A. A. Lapkin, B. A. Cressey, Trans. Inst. Metal Finishing 2006, 84, 293.

[23] B. Zhu, Z. Sui, S. Wang, X. Chen, S. Zhang, S. Wu, W. Huang, Mater. Res. Bull. 2006, 41, 1097. doi:10.1016/J.MATERRESBULL. 2005.11.008

[24] S. H. Chien, Y. C. Liou, M. C. Kuo, Synth. Met. 2005, 152, 333 doi:10.1016/J.SYNTHMET.2005.07.254

[25] C. K. Lee, C. C. Wang, L. C. Juang, M. D. Lyu, S. H. Hung, S. S. Liu, Colloids Surf. A Physicochem. Eng. Asp. 2008, 317, 164 doi:10.1016/J.COLSURFA.2007.10.008

[26] S. Uchida, R. Chiba, M. Tomiha, N. Masaki, M. Shirai, Electrochemistry 2002, 70, 418

[27] Y. Ohsaki, N. Masaki, T. Kitamura, Y. Wada, T. Okamoto, T. Sekino, K. Niiharab, S. Yanagida, Phys. Chem. Chem. Phys. 2005, 7, 4157 doi:10.1039/B511016E

[28] M. S. Akhtar, J.-M. Chun, O.-B. Yang, Electrochem. Commun. 2007, 9, 2833. doi:10.1016/J.ELECOM.2007.10.005

[29] M. Wei, Y. Konishi, H. Zhou, H. Sugihara, H. Arakawa, J. Electrochem Soc. 2006, 153, A1232. doi:10.1149/1.2194667

[30] D. V. Bavykin, B. A. Cressey, F. C. Walsh, Aust. J. Chem. 2007, 60, 95. doi: 10.1071/CH06359

[31] D. V. Bavykin, B. A. Cressey, M. E. Light, F. C. Walsh, Nanotechnology 2008, 19, 275604. doi:10.1088/0957-4484/19/27/275604

[32] L. Yezek, R. L. Rowell, L. Holysz, E. Chibowski, J. Colloid Interface Sci. 2000, 225, 227. doi:10.1006/JCIS.2000.6753

[33] D. V. Bavykin, A. A. Lapkin, P. K. Plucinski, L. TorrenteMurciano, J. M. Friedrich, F. C. Walsh, Top. Catal. 2006, 39, 151. doi:10.1007/S11244-006-0051-4

[34] C. C. Tsai, H. Teng, Chem. Mater. 2004, 16, 4352. doi:10.1021/ CM049643U

[35] D. V. Bavykin, V. N. Parmon, A. A. Lapkin, F. C. Walsh, J. Mater Chem. 2004, 14, 3370. doi:10.1039/B406378C

[36] Q. Chen, G. H. Du, S. L.-M. Peng, Acta Crystallogr. B 2002, 58, 587 doi:10.1107/S0108768102009084

[37] N. Miyamoto, K. Kuroda, M. Ogawa, J. Phys. Chem. B 2004, 108 , 4268. doi:10.1021/JP035617S

[38] N. Miyamoto, K. Kuroda, M. Ogawa, J. Mater. Chem. 2004, 14, 165. doi:10.1039/B308800F

[39] S. Andersson, A. D. Wadsley, Acta Crystallogr. 1961, 14, 1245. doi:10.1107/S0365110X61003636

[40] D. Graham, J. Phys. Chem. 1955, 59, 896. doi:10.1021/J150531A022

[41] G. Calzaferri, S. Huber, H. Maas, C. Minkowski, Angew. Chem. Int. Ed. 2003, 42, 3732. doi:10.1002/ANIE.200300570

[42] E. Morgado, Jr, P. M. Jardim, B. A. Marinkovic, F. C. Rizzo, M. A. S. Abreu, J. L. Zotin, A. S. Araujo, Nanotechnology 2007, 18, 495710. doi:10.1088/0957-4484/18/49/495710

[43] J. Yu, M. Zhou, Nanotechnology 2008, 19, 045606. doi:10.1088/09574484/19/04/045606

[44] M. W. Xiao, L. S. Wang, Y. D. Wu, X. J. Huang, Z. Dang, J. Solid State Electrochem. 2008, 12, 1159. doi:10.1007/S10008-007-0466-2 